\title{
Елена Куварова
}

$$
|\mathbf{C}| \mathbf{O}|\mathbf{P}| \mathbf{E} \mid
$$

(iD https://orcid.org/0000-0002-2925-3648

Днепровский национальный университет имени Олеся Гончара

Факультет украинской и иностранной филологии и искусствоведения

Кафедра общего и славянского языкознания

49010, Украина,

2. Днепр, пр. Гагарина, 72

elkuvarova@gmail.com

\section{Рефлексивность частного письма как разновидности эго-текстов}

\section{Reflexivity of Private Letters as a Variety of Ego-Texts}

\begin{abstract}
Резюме
К числу актуальных проблем современной лингвистики принадлежит выяснение дифференциальных признаков эго-текстов (дневников, писем, мемуаров и т. п.) и изучение языковых средств объективации в этих текстах своего «Я». Целью данной работы было выяснить, как проявляется в текстах частных писем рефлексивность - один из существенных признаков эго-текстов. Материалом исследования стали опубликованные в разных изданиях письма русской интеллигенции XIX-XX вв. Показано, что рефлексивность является одной из основныХ категорий, присущих текстам частных писем, наряду с диалогичностью, с которой она соотносится по принципу взаимодополнения на оси коммуникации «адресант - адресат». Исследованный эпистолярий фиксирует разные типы рефлексии: личностную, коммуникативную, интеллектуальную, кооперативную, языковую. Рефлексивность проявляется в эпистолярном тексте такими языковыми средствами, как использование личных и притяжательных местоимений первого лица, местоимений себя, свой; включение в текст письма высказываний, peализующих речевой жанр самопрезентащия; широкое употребление эмотивной лексики; воспроизведение средствами синтаксической стилистики некоторых свойств внутренней речи.
\end{abstract}

Ключевые слова: письмо, эго-текст, рефлексия, рефлексивность, адресант, самопрезентация.

\section{Summary}

Among the pressing problems of modern linguistics, there is the clarification of differential signs of ego-texts (diaries, letters, memoirs, etc.) and the study of the linguistic means of objectification of self in these texts. The purpose of this work was to find out how reflexivity, as one of the essential attributes of ego-texts, is manifested in private letters. The material of the study was a complied set of letters of the Russian intelligentsia of the $19^{\text {th }}$ and $20^{\text {th }}$ centuries. It was demon- 
strated that reflexivity is one of the main categories inherent in the texts of private letters, along with the dialogic nature to which it relates in line with the principle of complementarity along the line of "addresser - addressee" communication. The studied epistolary work conveys different types of reflection: personal, communicative, intellectual, cooperative, linguistic. Reflexivity is manifested in epistolary texts by such linguistic means as the use of personal and possessive pronouns in the first person, the use of reflexive pronouns, the inclusion in the text of statements that implement the 'self-presentation' speech genre; a widespread use of emotive vocabulary; reproduction of some properties of internal speech by means of syntactic stylistics.

Keywords: letter, ego-text, reflection, reflexivity, addresser, self-presentation.

Последние десятилетия характеризуются возросшим интересом филологов к изучению так называемых автодокументальных текстов: дневников, писем, автобиографий, мемуаров, интервью и т. п. Эти тексты принадлежат к разным жанрам, но объединены они тем, что в значительной мере сосредоточены на личности их создателя, на проблематике самопознания, самоидентификации, самовыражения. Осмысление таких документов, в которых личность запечатлевает себя, даёт возможность не только изучить факты биографии пишущего, события, свидетелем и участником которых он был, но и в известной мере проникнуть в работу памяти, мышления, в механизмы коммуникативной деятельности, а в целом - глубже заглянуть в своё культурное прошлое, разглядеть в нём истоки настоящего. Такого рода речевые произведения объединены термином «эго-текст», который философ С.И. Митина определяет как «корпус автобиографических текстов, существующий в многообразии жанров, скрепой которых является авторское «Я», выступающее генерирующим центром идей, переживаний и действий» (Митина, 2008, 3). Эго-тексты изучаются в разных аспектах: философском, психолого-педагогическом, лингвокультурологическом и собственно лингвистическом, предполагающем, в частности, выяснение дифференциальных признаков эго-текстов и изучение языковых средств объективации своего «Я» в текстах различной жанрово-стилистической принадлежности.

Определяя эго-текст с филологической точки зрения, М.Ю. Михеев указывает на два его существенных признака:

(1) это текст о себе самом, то есть имеющий своим объектом обстоятельства жизни самого автора, и (2) - текст, написанный с субъективной авторской точки зрения, то есть человеком из эгоцентрической позиции» (Михеев, 2007, 5).

Если рассматривать названные признаки как инвариантную составляющую комплекса жанровых характеристик эго-текстов, то во всём массиве соответствующих речевых произведений можно выделить ядерную зону, куда, несомненно, попадут дневниковые тексты, наиболее полно и последова- 
тельно реализующие инвариант данного текстотипа, и зону периферийную, объединяющую речевые жанры, для которых набор дифференциальных признаков будет так или иначе варьироваться. При этом учёные не раз отмечали глубинную связь личных дневников с письмами: А.И. Ефимов, например, и те, и другие объединял понятием «эпистолярный стиль» (Ефимов, 1961, 16); высказывалась также мысль о том, что «возможно было бы вывести весь жанр пред-текста (или дневниковой прозы) - из жанра эпистолярного, если не генетически, то, по крайней мере, типологически» (Михеев, 2007, 73). В связи с этим актуальным представляется вопрос о характере взаимосвязи дневниковых и эпистолярных текстов: об их общих и дифференциальных признаках, влиянии и взаимодействии этих жанров.

Существенными признаками частного письма, по мнению Т.П. Акимовой, являются «свободная композиция, политематичность, мозаичность, обусловленные тем, что эпистолярный текст представляет собой беседу „через время и пространство”, письмо является неким суррогатом непосредственного, „живого” общения» (Акимова, 2011, 17). Полагаем, что все названные качества могут быть присущи также и дневниковым записям. Ограничения существуют, правда, в отношении свободы композиции: эпистолярный текст, как правило, включает в себя ряд структурных параметров (обращение, приветствие, дата и место написания, подпись, этикетные формулы), которые, собственно, и дают основания квалифицировать некоторый текст как письмо. У дневниковых записей таких параметров меньше, но дата (а возможно, место и время написания) обычно предваряют содержательную часть.

Главное отличие эпистолярных и дневниковых текстов заключается в характере адресации: письмо - это всегда текст, обращённый к другому человеку, ориентированный на прочтение адресатом, вследствие чего «в качестве доминантной категории текста письма... рассматривается диалогизация, которая реализуется системой языковых средств, в том числе обращением и подписью адресанта» (Белунова, 2000, 111). Дневнику же присуща автоадресованность, обращённость автора к себе, возможно, к себе - будущему, с расчётом на то, что дневниковые записи когда-либо будут перечитываться и восприниматься с позиций иного возраста и опыта. Дневниковые записи делаются человеком для себя, и тем не менее указанная оппозиция «автоадресация - ориентация на внешнего адресата» не столь безусловна, как это кажется на первый взгляд, хотя бы уже потому, что автор дневника (и это не раз отмечали исследователи дневниковых текстов) может предполагать, иногда с опаской или, наоборот, с надеждой, что его дневник прочтут и другие люди, а возможно, он будет опубликован и обретёт массового читателя (Зализняк, 2010, 166-167).

С другой стороны, известны случаи, когда письма пишутся не только для человека, которому они формально адресованы, но также и для себя. Русский врач-хирург Н.И. Пирогов, возглавивший организацию медицин- 
ской помощи во время Крымской войны 1854-1855 гг., в одном из первых своих писем жене из Севастополя замечал:

Пишу, милая Саша, не для тебя одной, а и для других добрых людей, а главное, и для себя, может быть (Н.И. Пирогов - А.А. Пироговой, 14.11.1854).

Этот мотив, связанный не только с передачей информации, но и сохранением её для самого автора писем с целью использования в будущем, был реализован впоследствии: существуют свидетельства, что на факты, изложенные в письмах, их автор позже опирался и в своих научных трудах, и в мемуарно-автобиографической прозе. Подобная интенция реализуется в письмах, адресованных близким людям, членам семьи, поскольку именно это обстоятельство даёт основания автору полагать, что отправленные кому-то другому письма через некоторое время окажутся доступными и для него самого.

Письмо иногда приобретает и структурно-композиционное членение, характерное для дневника. Это бывает в ситуации, когда послание имеет большой объём и пишется на протяжении нескольких дней, или в том случае, если автор не имеет возможности отправить его сразу, будучи, например, в пути, и дописывает текст в несколько приёмов. Так, в одном из писем А.И. Герцена невесте, написанном по дороге из Вятки во Владимир в течение нескольких дней и состоящем из нескольких частей, каждая часть ограничена указанием даты и места написания или даты и времени подобно тому, как маркируются обычно дневниковые записи:

Яранск, 30 декабря 1837 _..> Ночь с 31 дек. на 1 янв. 1838 г. Поляны. 46 верст от Нижнего. 〈... Нижний-Новгород. 1 января 1838 ‘..> 3 января. Владимир 〈... 3-го вечером 〈...〉 4-го, вторник ‘... Прощай же, ангел. Твой Александр (А.И. Герцен - Н.А. Захарьиной, 30.12.1837-4.01.1838).

Каждая часть этого письма включает обращение к адресату и заключительные этикетные формулы и представляет собой относительно самостоятельный фрагмент текста.

В качестве существенного признака эго-текстов О.Д. Козлова и Л.В. Кушнина называют «рефлексивную составляющую» (Козлова, Кушнина, 2012). Понятие «рефлексия» очень многогранно, оно изучается в разных областях науки: философии, психологии, языкознании, когнитивной лингвистике. В философии под рефлексией понимается «форма теоретической деятельности человека, которая направлена на осмысление своих собственных действий, культуры и ее оснований; деятельность самопознания, раскрывающая специфику душевно-духовного мира человека» (Огурцов, 2010, 445). В социальной психологии рефлексия означает «умение индивида осознавать то, как он воспринимается другими людьми, партнерами по общению» 
(Баранова, 2015, 471). Исследователи рефлексии различают разные её типы: внешнюю, направленную на объекты внешнего мира и деятельность субъекта в этом мире, и внутреннюю, направленную на внутренний мир личности (Шадриков, 2014); кооперативную (знания о ролевой структуре и организации взаимодействия в коллективе), коммуникативную (представления о внутреннем мире другого человека и причинах тех или иных его поступков), личностную (свои поступки и образы собственного «я» как индивидуальности), интеллектуальную (знания об объекте и способах действия с ним) (Степанов, Семенов, 1985, 36); личностную (рефлексия на себя) и социальную (рефлексия на других) (Чурилова, 2016).

Психолог Г.В. Ожиганова обосновала необходимость разграничить понятия «рефлексия» (процесс) и «рефлексивность» (свойство, качество) (Ожиганова, 2018, 59). Рефлексия тесно связана с текстовой деятельностью человека: не случайно Е.Б. Старовойтенко предлагает метод моделирования индивидуальности с помощью рефлексивных литературных Я-текстов (Старовойтенко, 2007), что реализуется в педагогике, в частности, рекомендациями студентам педагогического вуза вести рефлексивный дневник (Баранова, 2015). И если рефлексия рассматривается как процесс познания себя, то свойство текста запечатлевать, выражать и отражать этот процесс можно назвать рефлексивностью. В то время, как, скажем, личному дневнику рефлексивность присуща, безусловно, что детерминировано уже природой этого жанра, предполагающего автоадресованность записей, рефлексивность писем, с их ориентацией на внешнего адресата, нуждается в обосновании. Целью данной работы было выяснить, как проявляется рефлексивность в текстах частных писем. Материалом исследования стали опубликованные в разных изданиях письма русской интеллигенции XIX-XX вв.

$\mathrm{B}$ письмах находят своё отражение различные типы рефлексии. Проиллюстрируем это следующими примерами. Самые разнообразные проявления личностной рефлексии находим в переписке П.И. Чайковского и Н.Ф. фон Мекк, которых связывал эпистолярный роман продолжительностью более десяти лет. Такие глубоко интимные переживания, как эмоциональное восприятие музыки П.И. Чайковского, ценность потаённых душевных движений, опасения показаться смешной, зафиксированы в письме великому композитору от поклонницы его творчества:

...поклонение такого ничтожного существа в музыке, как я, может показаться Вам только смешным, а мне так дорого мое наслаждение, что я не хочу, чтобы над ним смеялись, поэтому скажу только и прошу верить этому буквально, что с Вашею музыкою живется легче и приятнее (Н.Ф. фон Мекк - П.И. Чайковскому, 18 декабря 1876 г.).

Личностная рефлексия включает не только описание своих эмоций, но и анализ психофизиологических свойств собственной личности. Пример 
такого анализа мизантропии, рассматриваемой как болезнь, т. е. патологическое качество личности, находим в письме П.И. Чайковского, который раскрывает динамику своего состояния, борьбу с самим собой, делится найденным средством преодоления душевного недуга:

\begin{abstract}
Уж одно то, что мы страдаем с Вами одною и тою же болезнью, сближает нас. Болезнь эта - мизантропия, но мизантропия особого рода, в основе которой вовсе нет ненависти и презрения к людям. Люди, страдающие этой болезнью, боятся не того вреда, который может воспоследовать от козней ближнего, а того разочарования, той тоски по идеалу, которая следует за всяким сближением. Было время, когда я до того подпал под иго этого страха людей, что чуть с ума не сошел. Обстоятельства моей жизни сложились так, что убежать и скрыться я не мог. Приходилось бороться с собой, и единый бог знает, чего мне стоила эта борьба.

Теперь я уже вышел настолько победителем из этой борьбы, что жизнь давно перестала быть невыносимой. Меня спасает труд, - труд, который в то же время и наслаждение. К тому же, благодаря нескольким успехам, выпавшим на мою долю, я очень ободрился, и хандра, доходившая прежде до галлюцинаций и безумия, посещает меня редко (П.И. Чайковский - Н.Ф. фон Мекк, 16 марта 1877 г.).
\end{abstract}

С личностным типом рефлексии тесно связана коммуникативная рефлексия. Как отмечает Т.В. Радзиевская, в письмах, в отличие, например, от дневников, лучше всего выявляется способность автора к диалогу, интерактивному речевому поведению, степень учёта интересов адресата, выполнение им основных постулатов общения, конкретные речевые привычки, лексические и синтаксические предпочтения (Радзиевская, 2010, 445). Людям свойственно делиться сокровенными мыслями о себе и своих чувствах с теми, кому они могут доверять, в ком предполагают найти способность испытывать такие же или подобные чувства, кто обладает опытом духовной жизни, обеспечивающим понимание, и не случайно в приведенном выше примере самоанализу предпослано замечание, что автора письма сближает с адресатом то, что они страдают одною и тою же болезнью. Ещё один пример коммуникативной рефлексии - размышления о том, что́ является основой общения и духовной близости людей:

Мне кажется, что ведь не одни отношения делают людей близкими, а еще более сходство взглядов, одинаковые способности чувств и тождественность симпатий, так что можно быть близким, будучи очень далеким (Н.Ф. фон Мекк - П.И. Чайковскому, 7 марта 1877 г.).

Интеллектуальная рефлексия, т.е. рассуждения об объекте, на который направлены действия автора письма, часто связана с его профессиональной деятельностью. Естественно, скажем, что в письмах Н.И. Пирогова периода его работы в Севастополе значительное место занимают мысли об оптимальных способах организации медицинской помощи раненым и больным. Рассказ о происходящих событиях (прибытие общины сестёр милосердия, 
их работа в госпиталях) врач заключает генерализованным высказыванием, в котором даёт оценку нового опыта, полученного им в процессе организации работы сестёр милосердия, которую он курировал:

Дней пять тому назад приехала сюда Крестовоздвиженская община сестер Елены Павловны, числом до тридцати, и принялась ревностно за дело; если они так будут заниматься, как теперь, то принесут, нет сомнения, много пользы. Они день и ночь попеременно бывают в госпиталях, помогают при перевязке, бывают и при операциях, раздают больным чай и вино и наблюдают за служителями и за смотрителями и даже за врачами. Присутствие женщины, опрятно одетой и с участием помогающей, оживляет плачевную юдоль страданий и бедствий (Н.И. Пирогов - А.А. Пироговой, 6 декабря 1854 г.).

Интеллектуальная рефлексия предполагает анализ источников информации, достоверности полученных сведений и - на этой основе - прогнозирование, которое лежит в основе целеполагания и дальнейшей активности действующего субъекта. Вот пример из письма Н.И. Пирогова, в котором он пытается оценить перспективы Крымской военной кампании 1854-1855 гг:

Что делается в Балаклаве, мало известно; словам пленных и перебежчиков нельзя верить, а других лазутчиков, кажется, у нас нет; в какой мере англичане и французы терпят, мы знаем только из газет и от дезертиров. Конца ещё не скоро предвидится, но, кажется, наступление весны в феврале должно же что-нибудь решить, кто сильнее и настойчивее (Н.И. Пирогов - А.А. Пироговой, 13 января 1855 г.).

Актуальность кооперативной рефлексии для участников эпистолярного общения возрастает в ситуации, когда переписка оказывается включённой в какую-либо другую деятельность, осуществляемую коммуникантами совместно. В таком случае письма становятся инструментом «настройки», организации кооперативного взаимодействия, распределения обязанностей и полномочий между участниками общения, согласования их позиций и постановки общих задач. Творческая, продуктивная деятельность, которая опирается на воображение, интуицию, фантазию, включает и рефлексивную составляющую, которая касается, в частности, оценки действий адресата в ходе его сотрудничества с адресантом. Пример кооперативной рефлексии находим, в частности, в письме М.А. Булгакова К.С. Станиславскому, написанном после очередной репетиции во время их совместной работы над инсценировкой «Мёртвых душ» во МХАТе:

Цель этого неделового письма выразить Вам то восхищение, под влиянием которого я нахожусь все эти дни. В течение трёх часов Вы на моих глазах ту узловую сцену, которая замерла и не шла, превратили в живую. Существует театральное волшебство!

Во мне оно возбуждает лучшие надежды и поднимает меня, когда падает мой дух. Я затрудняюсь сказать, что более всего восхитило меня. Не знаю, по чистой совести. Пожалуй, Ваша фраза по образу Манилова: «Ему ничего нельзя сказать, ни о чём нельзя спро- 
сить - сейчас же прилипнет», - есть высшая точка. Потрясающее именно в театральном смысле определение, а показ - как это сделать - глубочайшее мастерство!

Я не беспокоюсь относительно Гоголя, когда Вы на репетиции. Он придёт через Вас. Он придёт в первых картинах представления в смехе, а в последней уйдёт, подёрнувшись пеплом больших раздумий. Он придёт (М.А. Булгаков - К.С. Станиславскому, 31.12.1931).

Особый тип, который получает отражение в письмах, - это языковая рефлексия, трактуемая в широком понимании как «рефлексия по отношению ко всему, что имеет какое-либо отношение к языку и его использованию» (Шмелева, 1999, 109). При узком понимании этого термина языковая рефлексия отождествляется с понятиями «комментарий», «оценка», «толкование», которые представляют собой вербальную экспликацию размышлений говорящего над собственной речевой деятельностью, комментарий по поводу выбора слова (Вепрева, 2005, 76). Такие размышления естественным образом сопровождают текстовую деятельность людей, чьи профессиональные интересы сосредоточены в сфере словесного творчества, - поэтов, писателей, журналистов, литературных критиков и т. п. Так, письма М.А. Булгакова содержат многообразные проявления языкового самосознания писателя. Внимательное отношение к выбору слова отражают пояснения, сопровождающие словоупотребление:

Ты спрашиваешь, как я поживаю. Хорошенькое слово. Именно я поживаю, а не живу (М.А. Булгаков - К.П. Булгакову, 1.02.1921).

Авторские комментарии касаются как семантики, так и стилистической окраски слова:

Радикулит? Как это по-учёному называется? (М.А. Булгаков - П.С. Попову, 14.03.1934).

Метаязыковые комментарии в эпистолярии Булгакова охватывают весь процесс вербальной коммуникации, начиная от замысла высказывания до его реализации. Реагируя на короткое письмо Е.И. Замятина, Булгаков указывает на своё коммуникативное намерение ответить ему таким же кратким посланием, - намерение, которое, однако, трансформируется уже в процессе общения:

Зачем же, о Странник, такая скупость на слова? Хотел отомстить Вам тем же, но желание говорить о драматургии берет верх (М.А. Булгаков - Е.И. Замятину, 28.10.1932). В письмах эксплицировано и действие механизма коммуникативного контроля, сверки текста с авторским замыслом, лежащим в основе его порождения: Хотел написать тебе длинное письмо с описанием Москвы, но вот что вышло... (М.А. Булгаков - Н.А. Земской, 1.12.1921). 
Письма Б.Л. Пастернака, адресованные М.И. Цветаевой, содержат множество высказываний, отражающих рефлектирующую деятельность поэта в отношении создаваемого им текста. Нередко Пастернак даёт собственным словам оценку - как прямую, с помощью оценочных предикатов:

Мне не нравятся последние три слова (Б.Л. Пастернак - М.И. Цветаевой, 25.03.1926),

- так и косвенную, в метафорических высказываниях:

семинарское удручающее однословье; либреттные формулировки; галерочное, парикмахерское слово; положительная загадочность слова и т.п.

Метаязыковые комментарии в письмах Пастернака касаются также распределения информации между текстами писем:

O Rilke, куске нашей жизни, о человеке, приглашающем нас с тобой в Альпы будущим летом, - потом, в другом письме; О мире дальше. Всего сразу не сказать; Об этом в другом, в следующем письме;

характеризуют способ развертывания текста - плавный или прерывный: но тут нельзя останавливаться и надо прибавить...; обозначают цель высказывания: Я задам тебе сейчас вопрос...; сигнализируют смену темы: $A$ mеперь о тебе; наличие подтекстовой информации:

Ты мне напомнила о нашем боге, обо мне самом, о детстве, о той моей струне, которая склоняла меня всегда смотреть на роман как на учебник (ты понимаешь чего) и на лирику как на этимологию чувства (если ты про учебник не поняла) (Б.Л. Пастернак - М.И. Цветаевой, 25.03.1926).

Языковая рефлексия, отражающая аналитическую деятельность сознания автора письма, направленную на осмысление разных этапов процесса порождения высказывания: от формирования мотива и планирования речевой деятельности до выбора слов - способствует организации коммуникативной деятельности адресанта, обеспечивая адекватность понимания авторского замысла адресатом.

Проявления в письмах рефлексии разных видов: личностной, коммуникативной, интеллектуальной, кооперативной, языковой - формирует такое качество эпистолярного текста, как рефлексивность. Лингвистически рефлексивность в частном письме выражается такими средствами:

а) использование личных и притяжательных местоимений первого лица, указывающих на адресанта, а также местоимений себя, свой. Эти местоимения являются маркерами авторского повествования от первого лица, рассказа о себе, своих взглядах, чувствах и мыслях: 
Я ведь не только женат, $я$ ещё и $я$, и $я$ полуребёнок. Т. е. у меня нет в этом частоты, которая грозила бы опасностью самоискаженья. (...) Посылаю тебе фотографию. Я ужасно безобразен. $Я$ именно таков, как на фотографии - она удачна. $Я$ только щурюсь, потому что смотрю на солнце, что и делает её особенно неприятной (Б.Л. Пастернак - М.И. Цветаевой, 20.04.1926).

б) включение в текст письма высказываний, реализующих речевой жанр самопрезентация, т. е., по определению А.В. Курьянович, «тип текста, появление которого обусловлено авторской целевой установкой самоподачи, самохарактеризации и самораскрытия в условиях определенной ситуации общения〉 (Курьянович, 2006, 145). Самопрезентация осуществляется на разных уровнях: это портретная и возрастная самохарактеристика, сообщение автобиографических сведений, описание физического самоощущения, исполняемых социальных ролей, психосоматических ощущений - всего, что помогает человеку решить задачу самоопределения, поиска личностной идентичности. Таковы, например, приведённые выше высказывания в письме Б.Л. Пастернака.

в) использование эмотивной лексики, сопровождающее процесс рефлексии, поскольку мышление человека неразрывно связано с эмоциями, о чём Л.С. Выготский писал: «Кто оторвал мышление... от аффекта, тот навсегда закрыл себе дорогу к объяснению причин самого мышления» (Выготский, $1982,21)$. Опираясь на функционально-семантическую классификацию лексики эмоций, описанную в монографии Л.Г. Бабенко (Бабенко, 1989, 71-81), только в языковом материале, уже представленном ранее в данной статье, употреблены лексемы, обозначающие эмоциональное состояние: поклонение, наслаждение, мизантропия, хандра, ненависть, презрение, желание, разочарование тоска, страх, восхищение, страдания, бедствия, надежда, хотеть, страдать, бояться, беспокоиться, страдающие; становление эмоционального состояния: сближение, очаровываться; эмоциональное воздействие: отомстить; эмоциональное отношение: симпатия, благодарный, верить, терпеть, восхитить, нравиться, с участием; внешнее выражение эмоций: смеяться, смех; эмоциональную характеризацию: милый, добрый, неприятный, удачный, безобразный, невыносимый, ничтожный, смешной, потрясающий, удручающий, плачевный, дорого, легко, приятно, ревностно. Эти лексемы представляют широкий спектр разных эмоций как в плане денотативно-эмотивных, так и коннотативно-эмотивных смыслов;

г) синтаксис высказываний и целых фрагментов текста, где реализуется рефлексивность, может воспроизводить некоторые свойства внутренней речи, сближая стилистику эпистолярного текста с текстом дневниковым. Автоадресованность последнего позволяет автору не соблюдать строго все нормы языка, в результате чего текст включает множество неполных или односоставных номинативных предложений, вставные конструкции, самоперебивы, вопросно-ответные единства, как это бывает в мысленном диало- 
ге с самим собой. Отдельные письма М.И. Цветаевой включают фрагменты с такой синтаксической структурой, например:

Осень 1921 г. Моя трущоба в Борисоглебском переулке. Вы в дверях. Письмо от И.Г. 〈... - pасспросы: «Как живете? Пишете ли? Что - сейчас - Москва?» и Ваше - как глухо! - «Река... Паром... Берега ли ко мне, я ли к берегу... А может быть, и берегов нет... А может быть и... - И я, мысленно: Косноязычие большого. - Темно́ты (М.И. Цветаева - Б.Л. Пастернаку, 29.06.1922).

Синтаксис этой части письма, где автор излагает своё воспоминание о встрече, произошедшей почти годом ранее, фиксирует работу человеческой памяти, в которой событие может храниться как результат симультанного восприятия и впоследствии синтезироваться из отдельных деталей, элементов, которые произвели впечатление.

Таким образом, рефлексивность как существенный признак эго-текстов является одной из основных категорий, присущих текстам частных писем, наряду с диалогичностью, с которой она соотносится по принципу взаимодополнения на оси коммуникации «адресант - адресат». Эпистолярий адресантов - представителей русской интеллигенции XIX-XX вв. - фиксирует разные типы рефлексии: личностную, коммуникативную, интеллектуальную, кооперативную, языковую. Рефлексивность проявляется в эпистолярном тексте такими языковыми средствами, как использование личных и притяжательных местоимений первого лица, местоимений себя, свой; включение в текст письма высказываний, реализующих речевой жанр самопрезентацุия; широкое употребление эмотивной лексики; воспроизведение средствами синтаксической стилистики некоторых свойств внутренней речи.

\section{БИБЛИОГРАФИЯ}

Акимова, Т.П. (2011). Хронотоп эпистолярного текста (на материале писем А.С. Пушкина и М. Горького), Вестник Волгоградского гос. ун-та. Серия 2. Языкознание. № 2(14), 17-22. Бабенко, Л.Г. (1989). Лексические средства обозначения эмоций в русском языке. Свердловск: Издательство Уральского университета.

Баранова, О.И. (2015). Рефлексивный дневник студента педагогического вуза в аспекте акмеологического подхода, Современные наукоемкие технологии. № 12-3, 471-475. URL: http://www.top-technologies.ru/ru/article/view?id=35295 (доступ: 15.02.2020).

Белунова, Н.И. (2000). Дружеские письма творческой интеллигенциии конца XIX - начала $X X$ в. (Жанр и текст писем). Санкт-Петербург: Издательство Санкт-Петербургского университета.

Вепрева, И.Т. (2005). Языковая рефлексия в постсоветскую эпоху. Москва: ОЛМА-ПРЕСС.

Выготский, Л.С. (1982). Мышление и речь, Собрание сочинений: В 6-ти т. Т. 2. Проблемы общей психологии. Москва: Педагогика, 5-361. 
Ефимов, А.И. (1961). История русского литературного языка. Москва: Учпедгиз.

Зализняк, Анна А. (2010). Дневник: к определению жанра, НЛО. № 106, 162-180.

Козлова, О.Д., Кушнина, Л.В. (2012). Эго-текст в культурно-речевом пространстве, Современные проблемы науки и образования. № 4. URL: http://www.science-education.ru/ru/ article/view?id=6831 (доступ: 2.03.2020).

Курьянович, А.В. (2006). Когнитивная сущчность речевого жанра самопрезентация в эпистолярном дискурсе М.И. Цветаевой, Вестник Томского государственного педагогического университета. Вып. 5(56), 144-150.

Митина, С.И. (2008). Философский эго-текст: бытие в культуре: автореф. дисс. ... докт. филос. наук: 24.00.01 - Теория и история культуры. Саранск: Издательство Мордовского университета.

Михеев, М.Ю. (2007). Дневник как эго-текст (Россия, XIX-XX). Москва: Водолей Publ.

Огурцов, А.П. (2010). Рефлексия. В: Новая философская энииклопедия. Т. 3. (445-450), В.С. Степин, А.А. Гусейнов, Г.Ю. Семигин, А.П. Огурцов (науч.-ред. совет). Москва: Мысль.

Ожиганова, Г.В. (2018). Рефлексия, рефлексивность и высшие рефлексивные способности: подходы к разграничению, Вестник Костромского государственного университета. Серия: Педагогика. Психология. Социокинетика. Вып. 24. Т. 4, 56-60.

Радзієвська, Т.В. (2010). Нариси з конщептуального аналізу та лінгвістики тексту. Текст - соиіум - культура - мовна особистість. Київ: ДП «Інформаційно-аналітичне агентство».

Старовойтенко, Е.Б. (2007). Рефлексия личности в культуре, Мир психологии. № 4(52), 209-220.

Степанов, С.Ю., Семенов, И.Н. (1985). Психология рефлексии: проблемы и исследования, Вопросы психологии. № 3, 31-40.

Чурилова, Е.Е. (2016). Репрезентачия самосознания в личных дневниках современных девушек. Москва: Прометей.

Шадриков, В.Д. (2014). Мысль, мылиление и сознание, Мир психологии. № 1, 17-32.

Шмелёва, Т.В. (1999). Языковая рефлексия, Теоретические и прикладные аспекты речевого общения: Вестник Российской риторической ассоциации. Вып. 1(8). КрасноярскАчинск, 108-110.

$* * *$

Akimova, T.P. (2011). Khronotop epistolyarnogo teksta (na materiale pisem A.S. Pushkina i M. Gor'kogo), Vestnik Volgogradskogo gos. un-ta. Seriya 2. Yazykoznanie. № 2(14), 17-22.

Babenko, L.G. (1989). Leksicheskie sredstva oboznacheniya emotsii v russkom yazyke. Sverdlovsk: Izdatel'stvo Ural'skogo universiteta.

Baranova, O.I. (2015). Refleksivnyi dnevnik studenta pedagogicheskogo vuza v aspekte akmeologicheskogo podkhoda, Sovremennye naukoemkie tekhnologii. № 12-3, 471-475. URL: http://www.top-technologies.ru/ru/article/view?id=35295 (dostup: 15.02.2020).

Belunova, N.I. (2000). Druzheskie pis'ma tvorcheskoi intelligentsii kontsa XIX - nachala $X X v$. (Zhanr i tekst pisem). St. Petersburg: Izdatel'stvo Sankt-Peterburgskogo universiteta.

Churilova, E.E. (2016). Reprezentatsiya samosoznaniya $v$ lichnykh dnevnikakh sovremennykh devushek. Moscow: Prometei.

Efimov, A.I. (1961). Istoriya russkogo literaturnogo yazyka. Moscow: Uchpedgiz.

Kozlova, O.D., Kushnina, L.V. (2012). Ego-tekst v kul'turno-rechevom prostranstve, Sovremennye problemy nauki i obrazovaniya. № 4. URL: http://www.science-education.ru/ru/article/ view? $\mathrm{id}=6831$ (dostup: 2.03 .2020 ).

Kur'yanovich, A.V. (2006). Kognitivnaya sushchnost' rechevogo zhanra samoprezentatsiya $v$ epistolyarnom diskurse M.I. Tsvetaevoi, Vestnik Tomskogo gosudarstvennogo pedagogicheskogo universiteta. Vyp. 5(56), 144-150. 
Mikheev, M.Yu. (2007). Dnevnik kak ego-tekst (Rossiya, XIX-XX). Moscow: Vodolei Publ.

Mitina, S.I. (2008). Filosofskii ego-tekst: bytie $v$ kul'ture: avtoref. diss. ... dokt. filos. nauk: 24.00.01 - Teoriya i istoriya kul'tury. Saransk: Izdatel'stvo Mordovskogo universiteta.

Ogurtsov, A.P. (2010). Refleksiya. V: Novaya filosofskaya entsiklopediya. T. 3. (445-450), V.S. Stepin, A.A. Guseinov, G.Yu. Semigin, A.P. Ogurtsov (nauch.-red. sovet). Moscow: Mysl'.

Ozhiganova, G.V. (2018). Refleksiya, refleksivnost' $i$ vysshie refleksivnye sposobnosti: podkhody k razgranicheniyu, Vestnik Kostromskogo gosudarstvennogo universiteta. Seriya: Pedagogika. Psikhologiya. Sotsiokinetika. Vyp. 24. T. 4, 56-60.

Radziyevs'ka, T.V. (2010). Nary'sy' z konceptual'nogo analizu ta lingvisty'ky' tekstu. Tekst - socium - kul'tura - movna osoby'stist'. Ky'yiv: DP «Informacijno-anality'chne agentstvo».

Shadrikov, V.D. (2014). Mysl', myshlenie i soznanie, Mir psikhologii. № 1, 17-32.

Shmeleva, T.V.(1999). Yazykovaya refleksiya, Teoreticheskie i prikladnye aspekty rechevogo obshcheniya: Vestnik Rossiiskoi ritoricheskoi assotsiatsii. Vyp. 1(8). Krasnoyarsk-Achinsk, 108-110.

Starovoitenko, E.B. (2007). Refleksiya lichnosti v kul'ture, Mir psikhologii. № 4(52), 209-220.

Stepanov, S.Yu., Semenov, I.N. (1985). Psikhologiya refleksii: problemy i issledovaniya, Voprosy psikhologii. № 3, 31-40.

Vepreva, I.T. (2005). Yazykovaya refleksiya v postsovetskuyu epokhu. Moscow: OLMA-PRESS.

Vygotsky, L.S. (1982). Myshlenie i rech', Sobranie sochinenii: V 6-ti t. T. 2. Problemy obshchei psikhologii. Moscow: Pedagogika, 5-361.

Zaliznyak, Anna A. (2010). Dnevnik: k opredeleniyu zhanra, №O. № 106, 162-180.

\section{Источники фактического материала}

Булгаков, М.А. (2002). Собрание сочинений: в 8 m. Т. 8: Жизнеописание в документах, В.И. Лосев (сост., подготовка текста). Санкт-Петербург: Азбука-классика.

Герцен, А.И. (1958). Сочинения в 9 m. Т. 9. Дневник 1842-1845. Письма 1832-1870, Л.Р. Ланской (подгот. текста писем и прим.). Москва: ГИХЛ.

Переписка Бориса Пастернака (1990). Е.В. Пастернак и Е.Б. Пастернак (сост., подгот. текстов и коммент.). Москва: Художественная литература.

Пирогов, Н.И. (1950). Севастопольские письма и воспоминания, С.Я. Штрайх (ред.). Москва: Издательство АН СССР.

Чайковский, П.И. (2004). Переписка с Н. Ф. фон Мекк: в 3 кн. Кн. 1. 1876-1878 годы, И. Захаров (ред.). Москва: Захаров.

$* * *$

Bulgakov, M.A. (2002). Sobranie sochinenii: v 8 t. T. 8: Zhizneopisanie v dokumentakh, V.I. Losev (sost., podgotovka teksta). St. Petersburg: Azbuka-klassika.

Chaikovskii, P.I. (2004). Perepiska s N. F. fon Mekk: v 3 kn. Kn. 1. 1876-1878 gody, I. Zakharov (red.). Moscow: Zakharov.

Gertsen, A.I. (1958). Sochineniya v 9 t. T. 9. Dnevnik 1842-1845. Pis'ma 1832-1870, L.R. Lanskoi (podgot. teksta pisem i prim.). Moscow: GIKhL.

Perepiska Borisa Pasternaka (1990). E.V. Pasternak i E.B. Pasternak (sost., podgot. tekstov i komment.). Moscow: Khudozhestvennaya literatura.

Pirogov, N.I. (1950). Sevastopol'skie pis'ma i vospominaniya, S.Ya. Shtraikh (red.). Moscow: Izdatel'stvo AN SSSR. 